\title{
The role of corporate incubators as invigorators of innovation capabilities in parent companies
}

\author{
Jérôme Gonthier ${ }^{1}$ and Gabriel M. Chirita ${ }^{2^{*}}$ (D)
}

\author{
*Correspondence: gabriel_chirita@ \\ uqar.ca \\ ${ }^{2}$ Université du Québec à Rimouski \\ (UQAR), 300, allée des Ursulines, \\ Rimouski, QC G5L 3A1, Canada \\ Full list of author information is \\ available at the end of the article
}

\begin{abstract}
Companies need to rethink their innovation strategies in an increasingly disruptive business environment. The long-term success of large established companies depends not only on their ability to leverage their current capabilities and improve efficiency but also on taking risks and exploring unknown areas. To meet this challenge, established companies are increasingly relying on corporate incubators to fuel innovation and growth with entrepreneurial mindset. Drawing on Zollo and Winter's (Organization Science_13:339-351, 2002) deliberate learning model in conjunction with Christensen's [Christensen, C.M., Anthony S.D., and Roth E.A, Seeing What's Next? Using the Theories of Innovation to Predict Industry Change, 2004] resource-processes-values (RPV) theory, this paper attempts to answer the question "how can the entrepreneurial mindset fostered in corporate incubators drive the innovation capabilities in parent companies?" The study of four corporate incubators set up by companies from different industries reveals several factors that enable the entrepreneurial spirit fostered by corporate incubators to boost the innovation capability in their parent companies. These factors comprise the recruitment of employees with entrepreneurial potential, investments in knowledge articulation and codification, and a leadership that legitimizes the incubator as a means for the company to develop new ideas and provide support to entrepreneurs inside the organization.
\end{abstract}

Keywords: Corporate incubators, Innovation, Corporate entrepreneurship, Resource-based view, Deliberate learning

\section{Introduction}

The accelerating pace of technological change is leading to the redefinition of many industries, forcing companies to make innovation their priority (Dobbs, Manyika, \& Woetzel, 2016). To be able to compete with game-changing newcomers, large established companies increasingly look to start-ups as a significant source of innovation (Kohler, 2016). Start-ups launch new products and services and devise new business models that disrupt the competitive advantages of incumbent firms (Roessler \& Velamuri, 2015). Hence, although the evidence is far from comprehensive, start-ups are considered more innovative than established firms (Criscuolo, Nicolaou, \& Salter, 2012). To benefit from the entrepreneurial and innovative dynamism of start-ups, large

(c) The Author(s). 2019 Open Access This article is distributed under the terms of the Creative Commons Attribution 4.0 International License (http://creativecommons.org/licenses/by/4.0/), which permits unrestricted use, distribution, and reproduction in any medium, provided you give appropriate credit to the original author(s) and the source, provide a link to the Creative Commons license, and indicate if changes were made. 
companies have begun to set up corporate incubators, which have emerged as a modern tool for innovation management (Weiblen \& Chesbrough, 2015).

Becker and Gassmann (2006, p. 2) define corporate incubators as "specialized corporate units that hatch new businesses by providing physical resources and support" which is the definition we will adopt for the purposes of this paper. Their role is to develop new growth opportunities for the incubator's parent company (IPC) by enabling the development of small teams capable of operating in a more flexible and unbureaucratic environment, which certainly increases the pace of their actions. In addition, incubatees are encouraged to adopt alternative approaches that are innovative to IPC's traditional thinking and organizational patterns (Von Zedtwitz, 2003).

However, not all companies that have set up internal incubators fully exploit the true potential of these structures to generate innovation and strengthen their competitive advantage. The combination of entrepreneurial activity and corporate capabilities seems to be ideal for fostering innovative projects, but the inherent differences between large companies and start-ups make their collaboration a challenge (Kohler, 2016; Weiblen \& Chesbrough, 2015). To capitalize on incubatees' entrepreneurial mindset and innovative potential, IPCs must create the necessary conditions to detect and capture organizational learning occurring in their corporate incubators.

The existing literature offers many different best-practice approaches for corporate incubators (e.g., Kohler, 2016; Von Zedtwitz, 2003; Weiblen \& Chesbrough, 2015). But only limited attention is paid to the opportunity to foster entrepreneurial spirit within an organization through internal incubation. Therefore, we propose to answer the following question: "how can the entrepreneurial mindset fostered in corporate incubators drive the innovation capability in parent companies?" Using Zollo and Winter's (2002) deliberate learning model in conjunction with Christensen, Anthony, and Roth (2004) resource-processes-values model, we study four corporate incubators set up by companies from different industries in order to examine and explain the mechanisms by which the entrepreneurial mindset fostered within an incubation structure can be transferred back to its IPC.

\section{Literature review and concept definitions}

\section{Corporate incubators as a tool to achieve ambidextrous organization}

Most companies acknowledge the importance of innovation, yet often they struggle to put it into practice. Companies are confronted with an "innovation dilemma" (Christensen, 1997; Christensen, 2013), i.e., choosing between maintaining and developing the existing business or venturing into new areas. While dealing with their daily challenges and operations, many companies miss out on the innovative opportunities in new fields. Tushman and O'Reilly III (1996) suggested that organizations should become "ambidextrous" and combine exploitation and exploration instead of focusing on one aspect over the other. One approach to achieving an ambidextrous organization is to set up mandated units to engage in exploratory innovation activities as separate and distinct entities from the central organization (Christensen, 2013), but with integrating mechanisms Tushman and O’Reilly III (2004). 
Large established companies whose goal is to develop radical innovations while pursuing incremental gains (Tushman and O'Reilly III, 2004) have begun to set up internal incubation structures allowing company's employees or outsiders to pursue and develop risky business opportunities (Ford, Garnsey, \& Probert, 2010). Corporate incubators are thus considered an ideal way to create new skills (Becker and Gassmann, 2006; Keil, McGrath, \& Tukiainen, 2009; Vanhaverbeke \& Peeters, 2005) or new business models (Roessler \& Velamuri, 2015) for their IPCs.

Scholars highlight two fundamental characteristics of corporate incubators: (a) they are responsible for every step of developing and marketing a new product/service (Von Hippel, 1977), or business model (Roessler \& Velamuri, 2015), and (b) their role is to facilitate organizational learning in IPCs (Keil, McGrath, \& Tukiainen, 2009; Vanhaverbeke \& Peeters, 2005). Although authors such as Zahra, Nielsen, and Bogner (1999) stress the importance of seizing knowledge from corporate venture initiatives, none of the research conducted to date seems to have considered the incubatees' entrepreneurial mindset as an apprenticeship in itself with potential to influence the IPC's innovation capability.

\section{Entrepreneurial mindset}

The abundant literature on entrepreneurship, small business, innovation, or strategy has not yet formally addressed the invisible thread that links them all-the entrepreneurial mindset. The current prevalent entrepreneurship paradigm considers that the main role of entrepreneurs is to acquire knowledge and create social capital through innovation, risk-taking, pro-activity, network expansion, team spirit, the creation of organizations, and the creation of knowledge communities (Verstraete \& Fayolle, 2005). The synergy between entrepreneurship and innovation has the unique ability to give flexibility and self-renewal to any activity, which benefits business, industry, and society (Velamuri, 2002).

The notion of entrepreneurial mindset has been viewed as the motivation to enter and persist in the undertaking of new, innovative, and risky ventures (Bird, 1989). Entrepreneurial mindset implies the willingness to try new things or to do things differently because there is an opportunity for change (Block \& Stumpf, 1990), the ability to face the unknown, to experiment with new ideas, and to act with great openness and flexibility (Klapper \& Leger-Jarniou, 2006). Entrepreneurial mindset is about enthusiasm, commitment, perseverance, and risk-taking related to the pursuit of business ventures, and considered necessary for success (Klinger \& Schundeln, 2011).

As we can discern from all these definitions, entrepreneurial mindset represents a specific state of mind that directs human behavior toward opportunities, innovation, and value creation. Thus, entrepreneurial mindset refers both to a state of mind and to a dynamic of action. Its attributes include strength of conviction, persistence, and the ability to take calculated risks and to accept uncertainty. But beyond these characteristics, which reflect a state of mind, entrepreneurs distinguish themselves by their ability to apprehend change, to identify growth opportunities, and to make innovation happen. In this paper, we draw on Haynie, Shepherd, Mosakowski, and Earley's (2010) definition of entrepreneurial mindset, which we describe simply as the ability to be agile and self-reliant in one's own cognitions, facing dynamic and uncertain work environments. 


\section{Research design and methods}

\section{Theoretical underpinning}

Teece, Pisano, and Shuen $(1997,2007)$ formulate the concept of dynamic capabilities as "the firm's ability to integrate, build, and reconfigure internal and external competences to address rapidly changing environments." According to Wang and Ahmed (2007), a firm's dynamic capabilities are the sum of three capabilities, namely to adapt, absorb, and innovate. The innovation capability refers to the competencies and knowledge used within a company to develop new products or markets by aligning an innovative strategic orientation with innovative processes and behaviors (Wang \& Ahmed, 2007).

To study the variation in innovation capability, we mobilize the theoretical framework of Christensen et al. (2004) on the resources, processes, and values (RPV) (Table 1). The RPV framework uses the firm's capabilities perspective to explain why established firms struggle to respond to disruptive innovations.

Zollo and Winter (2002) explain the formation of dynamic capabilities through intentional, cumulative, and repetitive learning processes. Learning occurs when a company invests in learning mechanisms. According to Zollo and Winter, there are three levels of investment in learning. The first is the knowledge accumulation by organizational routines and experience accumulation. Whatever the way a company operates, it will learn over time, trying out innovative and timely projects with specific employees. However, the learning that occurs in this context will mainly depend on people. They may disappear when the employee decides to leave the job. The second level is the knowledge articulation. This level occurs when individuals express their opinions and beliefs, engage in constructive discussions, and question the views of others. Knowledge is articulated through group discussions, debriefings, and performance evaluation processes. The third level, knowledge codification, requires higher cognitive efforts and allows employees to better understand what works, what does not, and why (Zollo \& Winter, 2002). In the codification process, the results of knowledge accumulation and articulation are recorded in guidebooks, databases, table sheets, decision support systems, and other tools to guide future actions. According to Zollo and Winter (2002), the more the heterogeneity of experience increases, the more knowledge codification is necessary to learn from experience accumulation.

Zollo and Winter argued that effective implementation of new learning is a four-step process. First, during the generative variation step, a company analyzes the

Table 1 Resources, processes, and values

\begin{tabular}{lll}
\hline Resources & Processes & Values \\
\hline Things or assets that organizations can buy & Established ways companies & The criteria by which prioritization \\
or sell, build, or destroy. & turn resources into products & decisions are made. \\
Examples: & or services. & Examples: \\
People & Examples: & Cost structure \\
Technology & Hiring and training & Income statement \\
Products & Product development & Customer demands \\
Equipment & Planning and budgeting & Size of opportunity \\
Information & Market research & Ethics \\
Cash & Resource allocation & \\
Brand & & \\
Distribution channels & & \\
\hline
\end{tabular}

Source: (Christensen et al., 2004: xviii) 
environment and uses its capabilities to address a challenge in an innovative way. New ideas and practices usually occur as a response to a combination of external or internal stimuli. They are subjected to an internal selection phase to assess their potential to improve the effectiveness of an existing capability. During the replication phase, the organization implements activities to disseminate recently approved change initiatives. Lastly, repetition leads to automatisms in the execution of a given task and a corresponding decrease in individual awareness and collective understanding of the linkages between action and performance.

\section{Theoretical model}

Drawing on the Christensen et al. (2004) RPV perspective of enterprise capabilities and Wang and Ahmed's (2007) classification of dynamic capabilities, we comprehend the innovation capability as the resources, processes, and values used by a company to develop new products, services, business models, or markets. Building on Zollo and Winter's (2002) deliberate learning model, we study the impact of the entrepreneurial mindset fostered in four corporate incubators on their respective IPC's innovation capability.

First, we present the level reached by each studied case according to Zollo and Winter's (2002) deliberate learning model. We then analyze the impact of the three learning mechanisms (knowledge accumulation, articulation, and codification) on the innovation

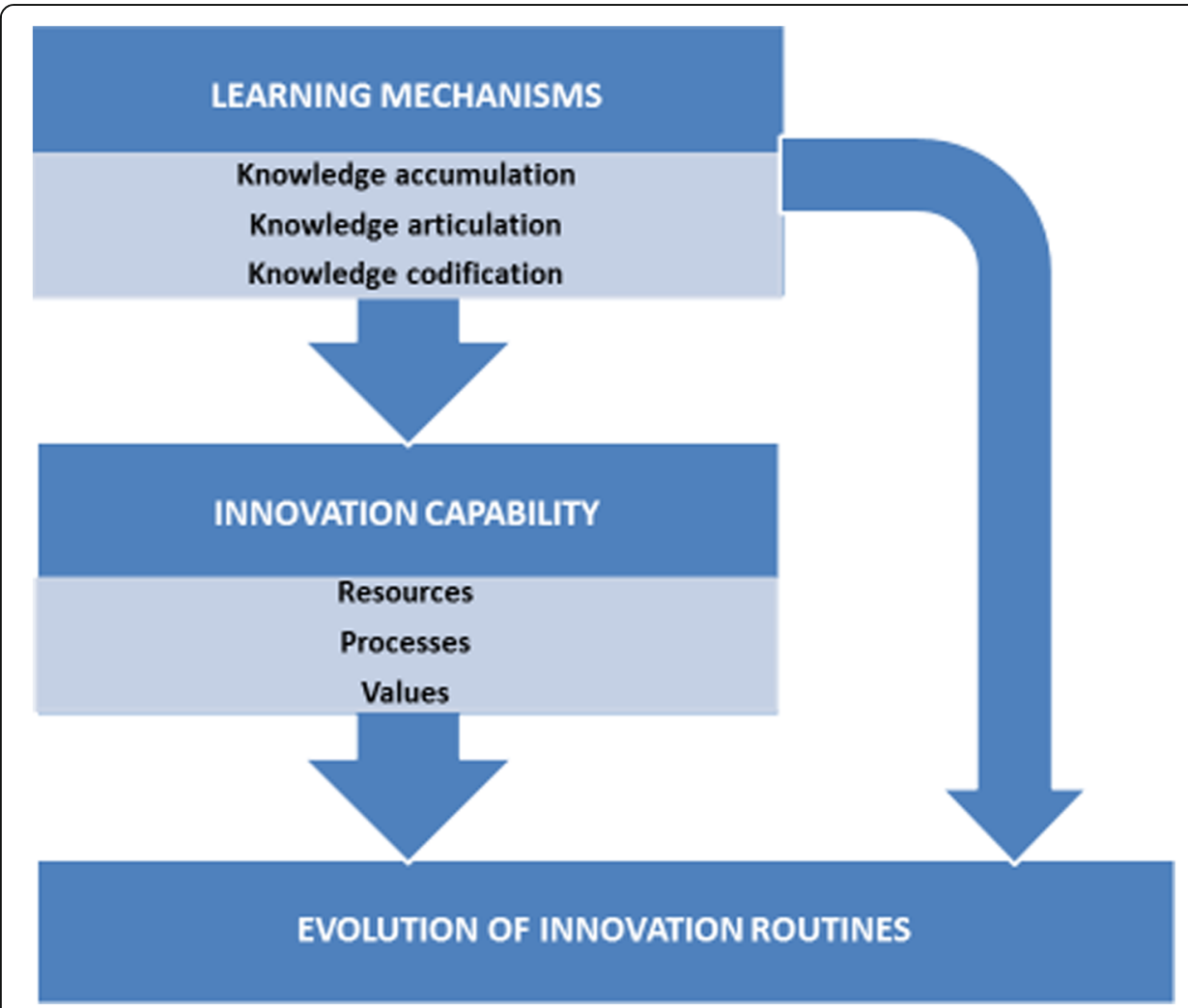

Fig. 1 Proposed theoretical framework, inspired by the work of Zollo and Winter (2002) and Christensen et al. (2004) 
capability dimensions, i.e., resources, processes, and values (Christensen et al., 2004). It is worth remembering that we study the impact of learning mechanisms only on the innovation capability as a form of dynamic capabilities (Wang \& Ahmed, 2007). Building on these theoretical grounds, we propose the following conceptual framework (Fig. 1).

\section{Sample selection and data collection and analysis}

Using qualitative method, our research focused on four IPCs: a Montreal-based company (IPC A) operating in the telecommunications sector and three companies based in Belgium, operating in three distinct sectors: aeronautics (IPC B), banking (IPC C), and pharmaceuticals (IPC D). All four companies had recently set up an internal incubation program.

Data were primarily gathered through open-ended and semi-structured interviews. In total, we conducted nine interviews, four in the Montreal company, two in the Belgian companies working in the banking and aeronautics sectors, and one in the pharmaceutical company. This sample proved to be sufficient to the extent that the informant's responses during the last interviews were predictable and allowed for a presumption of data saturation.

The data analysis followed accepted standards for qualitative research (Eisenhardt, 1989; Miles \& Huberman, 1994) and was conducted in three stages. First, the data analysis began by examining each case separately, including interviews, observations, and secondary sources. At this stage, we assessed to what extent our theoretical framework proved to be accurate in relation to the cases we studied. Second, cross-case analysis was conducted to compare findings and highlight the contrasts and similarities between cases (Yin, 2009). Third, to go beyond the initial impressions, the data were continually re-analyzed. Using a triangulation process, the data were examined by two researchers to enhance the reliability of the results.

\section{Case presentations: IPCs and their incubation programs}

IPC A operates in the telecommunications sector. It is part of a global conglomerate that employs 8000 people in 38 countries. Suffering from cut-throat competition, IPC A launched an incubation program under which any employee can submit an idea with potential to grow into a US $\$ 200$ million business within 3 years. By encouraging employees to be creative, IPA A strives to change the organizational culture to better adapt to the digital age challenges. Of all projects submitted, approximately $10 \%$ are selected to present a 5-min sales pitch followed by a Q \& A session with the company's senior management. The five finalist teams were invited on a week-long tour to Silicon Valley together with senior executives and outside experts, such as venture capitalists. During the trip, the finalists not only received training on technology trends and start-up management but also visited technology companies that have very different work styles from IPA A. At the end of the trip, the finalists made a final presentation to a panel of senior executives, venture capitalists, and other external experts. The winning teams left their positions and had 9 to 12 months to work full-time on their business projects. During the period, they earn the same salary.

IPC B is a global Belgian company active in the development, manufacturing, and assembly of advanced structures for civil, military, and space markets. Faced with the 
need to increase revenues to remain competitive, IPC B has focused its strategy on innovation through business diversification. This includes establishing partnerships with start-up companies and a program for motivated employees to submit their ideas to the CEO. The aim was to create a transversal organization capable of identifying innovative projects with the potential to generate an annual turnover of around 10 million euros over a 5-year horizon. The projects had to be in line with IPC B's ability to support the innovation process and, therefore, the ideas submitted need to pertain to the aeronautics sector. Ultimately, the plan was to spin off these projects to create subsidiaries in which IPC B would hold majority ownership, thereby enabling it to control their strategy.

Once selected to participate in the incubation program, the team proposing an innovative idea enters a 14-week program to validate the project's potential. During the first 7 weeks, incubatees are allowed to devote $50 \%$ of their time to the innovation project, with the remaining $50 \%$ to be used for their usual responsibilities. After this period, the team must present their progress to a small committee led by the CEO and convince him, without specific indicators, of the project's viability. If the project is considered to have potential, IPC B grants the team an additional 7 weeks to work on it, on a part-time basis. After these 14 weeks, if the project is still showing potential, the team will devote to its development full time. A business is spun off from IPC B, and the incubatees must leave their current employment to run the new joint venture.

IPC C is a Belgian banking institution offering individuals, companies, and public institutions a complete range of financial products and services. To stimulate the bank's employees and to attract new talent by projecting the image of an innovative company, the CEO decides in 2014 to set up an ideation program by means of an online collaborative tool to submit new ideas for the organization. The turnout was positive in the opinion of program managers, but little was done with the ideas submitted. The solution to exploit these ideas was to set up an internal incubator for projects that (1) have an impact on the bank's end customer and are not improvements in internal processes, (2) are disruptive and non-incremental, and (3) are transversal. The aim was to open the opportunity to innovate to all employees who would be interested, rather than limiting innovation activities to a few dozen people.

IPC D is a world-class healthcare company with three business units: pharmaceuticals, vaccines, and consumer healthcare. The reason for setting up an incubator within this company is different than in the above cases. For IPC D's incubator manager, the

Table 2 Respondents and IPCs sampled

\begin{tabular}{llll}
\hline Position of the interviewees & Sector of activity & Company & Company's home country \\
\hline Incubatee & Telecom & IPC A & Canada/India \\
Incubatee & & \\
Head of Innovation, Corporate Strategy & & \\
Senior Manager, Global Business Partner Team & Aeronautics & IPC B & Belgium \\
Incubatee & & & Belgium \\
$\begin{array}{l}\text { Development and Pre-Series Director } \\
\text { Incubatee }\end{array}$ & Banking institution & IPC C & Belgium \\
Head of Innovation & Health care & IPC D & Bum \\
Head of Innovation & & &
\end{tabular}


incubator was set up to "turn creativity into potential innovation for our company." The incubation initiative is part to the development of an innovation ecosystem within IPC D, which also includes three major R \& D labs, as well as relationships with universities, start-up companies, and research centers (Table 2).

\section{Results}

The data collected suggest three levels of influence of the entrepreneurial mindset fostered in the corporate incubator on the IPC's innovation capability. We examine the observed levels of influence in relation to the deliberate learning mechanisms that each IBC has implemented to capture the knowledge accumulated through incubation experience. We then analyze the impact of the observed levels of influence on the three dimensions of the innovation capability.

In Table 3 below, we outline our analysis of the data collected following our conceptual framework inspired by Zollo and Winter's (2002) deliberate organizational learning model and Christensen's (1997) RPV theory.

We consider de Zollo and Winter's (2002) four-step deliberate learning model as a continuum with the following sequence: generative variation, internal selection, replication, and retention. By setting up internal incubators, all IPCs have surpassed the phase of generative variation. Table 2 shows the highest level that each IPC reached under Zollo \& Winter's deliberate learning model. We first discuss the level of internal selection achieved by IPC C; then we move on to the level of replication achieved by IPCs A and $\mathrm{D}$ and conclude with a discussion of the level of retention achieved by IPC $\mathrm{B}$.

\section{Internal selection within IPC C}

According to Zollo and Winter (2002), internal selection consists in assessing new ideas and practices for their potential to improve the company's dynamic capabilities. At this stage, learning experiences are confronted with company's internal pressures. The strength of these pressures ultimately determines whether learning will be replicated on a larger scale.

\section{a. Level of influence observed}

In our opinion, the IPC C did not go beyond this level of integration with regards to entrepreneurial momentum, because when we conducted our interviews, it was clear that IPC C's employees were skeptical about the potential of the incubation initiative.

Table 3 Results summary

\begin{tabular}{lllll}
\hline Level of innovation capability evolution & Internal selection & Replication & Retention \\
\hline Representative case & & IPC C & IPC A and IPC D & IPC B \\
Investments in learning & Knowledge accumulation & High & High & High \\
& Knowledge articulation & Low/Medium & Medium & Medium \\
& Knowledge codification & Low/Medium & Low/Medium & High \\
Impact on innovation capability & Resources & Low & High & High \\
& Process & Low & Medium/High & High \\
& Values & Low & Low & High \\
\hline
\end{tabular}


First, none of the incubatees interviewed wanted to continue the incubation experience beyond the first 4 months of the program, being more interested in prioritizing their professional careers than in creating new value for their company. In our opinion, this situation has been fueled by a negative perception of the incubation initiative in the eyes of many:

Some people told us, "That must have been fun; you took four months off real work...".

Second, it appears that the advisory committee appointed to assist incubatees with their projects had not taken the approach seriously, nor had they attempted to integrate the methods and practices valued within the incubator. These two points indicate, in our view, strong pressures within the IPC $\mathrm{C}$ that run counter to the spread of entrepreneurial mindset. This is not surprising either, given the dominant culture ${ }^{1}$ within IPC $\mathrm{C}$, which is strongly influenced by banking sector regulations. Since the incubation initiative is very difficult to legitimize within IPC C, we consider that the seizing of the entrepreneurial dynamics that take place in the incubator is still only at the level of internal selection.

\section{Investments in Learning}

i. Knowledge accumulation

Despite its low level of legitimacy in IPC C, the incubation initiative proved to be an important source of accumulated experience for incubatees differing significantly from what they had usually been exposed to in their regular jobs. For this reason, we believe the level of knowledge accumulation through incubation is high.

Incubatees were involved in the product-development process of their start-up while in their regular jobs, they had not usually been concerned with such tasks. They also learned and put into practice entrepreneurial methods that favor prototyping, testing, and rapid iteration. Incubatees accumulated entrepreneurial experience over a long time-frame, which was much appreciated, according to the incubatees we interviewed.

\section{ii. Knowledge articulation}

We noted in the responses of the interviewees from IPC C a willingness to articulate knowledge stemming from their incubation experiences, but we did not receive confirmation that knowledge articulation actually occurred. In fact, one criticism put forward by the interviewed incubatees was the lack of opportunity offered by the IPC to share the learning that was gained during the incubation period: "The other interesting point to change would be to find ways for people to share and keep using the experience and knowledge gained during the incubation program with the bank."

We also noted that for one of our interviewees, the articulation of knowledge would have been very useful to gain legitimacy with colleagues who were not yet convinced by the relevance of the incubation initiative. Thus, we found a relatively weak articulation of knowledge at the incubatees' level, but a higher articulation at the level of IPC's Innovation Director. 
Our data do not indicate in any way that the IPC C codified the knowledge stemming from the learning that occurred in their incubator. We estimate that the investments in learning made by IPC $\mathrm{C}$ with respect to its incubation process were at a low level. Although investment in knowledge accumulation is high for the incubatees we interviewed, it appears that they had limited opportunities to share the learning they experienced. The entire articulation and coding effort were in the hands of the person in charge of the incubation. Given the low level of legitimacy of the incubation initiative within IPC $\mathrm{C}$, we conclude that the investment in learning does not yield the results expected by the incubator director.

b. Impact on innovation capability

i. Resources

The IPC C's incubation initiative has effectively led to tangible innovation results. Four of the five projects incubated generated results, mainly incremental and related to improving the bank's customer experience. On the other hand, our data do not indicate any examples suggesting that the company's innovation capability had a significant impact on its resources. Yet we believe the incubation actually influenced one particular resource, i.e., the incubatees themselves. However, this impact is limited because all incubatees have returned to their original business units composed of people reluctant to apply entrepreneurial principles in their ways of doing business.

\section{ii. Process}

The lack of legitimacy of the incubation initiative within IPC C appears to have hampered the imposition of this approach as an institutionalized innovation instrument. Nevertheless, we noted the management's willingness to improve the incubation model by enrolling the right people into the incubator.

iii. Values

It is significant that the incubator was not able to influence IPC C's dominant values. The director of innovation we met mentioned the sluggishness of the Belgian banking community as an incentive to set up an incubator. However, as soon as they left the incubator, the incubatees were pressured to comply with the bank's conservative values.

\section{Replication within IPCs A and D}

According to Zollo and Winter (2002), replication represents the knowledge integration stage where a company starts to disseminate change initiatives that were approved at the internal selection stage. At this stage, the IPC adapts the learning arising from the practices associated with new initiatives to improve existing processes and overall ways of doing business.

a. Level of influence observed 
We found that the cases of IPC A and IPC D represent companies that have succeeded to replicate their incubator-based learning in other innovation settings within the firm.

In the case of IPC A, the internal incubator was set up in response to the disruption of the telecommunications industry by technological shifts and new competition resulting from the spread of Internet-based communications services. The incubator was intended to be a critical force for growth and innovation by providing creative solutions to take advantage of the business opportunities created by technological change and by encouraging entrepreneurial mindset in the company's workforce. The ultimate goal was to transform the company's traditional approach to product development, based on technology push, into a market pull-oriented approach.

The outreach of the incubation initiative exceeded the influence level of internal selection since IPC A was able to use the incubator as a validation tool for the market pull approach. By assigning a skilled human resource to monitor and analyze the performance of new processes occurring in their incubator, IPC A showed that management was ready not only to widely disseminate the new practices but also to adapt them to different contexts.

In IPC D, incubation and diffusion of entrepreneurial mindset have reached the level of replication. Senior management relies on the incubatees' entrepreneurial mindset and methods to provide traditional company's R\&D units with the opportunity to try doing business differently. However, the use of internal incubation to develop new products, services, processes, or business models has its limitations in health services, due to extremely high regulatory and public-safety stakes, which may hinder the speed and agility so often attributed to an entrepreneurial mindset. But it should be noted that senior management is keen to disseminate incubatees, knowledge, and practices more widely throughout the company's product development processes.

\section{b. Learning mechanisms}

i. Knowledge accumulation

Knowledge accumulation through incubation activities was significant for IPC A and $\mathrm{D}$ incubatees. In the case of IPC A, the accumulation of experience began with the recruitment process. As part of an Idea Contest, employees were invited to come up with new solutions for growth. Finalists were sent to California to learn from start-up specialists and serial entrepreneurs. Knowledge accumulation then continued for employees retained for incubation as they entered a program where, for an extended period, they were completely autonomous in their decisions, budget allocation, and use of IPC's resources. According to the testimonies we gathered, this experience was transformative for incubatees:

Without having enough hindsight today to say so, I think that those who will stop their project and return to the company will have a completely different mindset. We do hope that this mindset will be instilled in the team and that it will have a multiplier effect. 
The IPC D's incubation program has relied on a frugality-based approach to speed up the idea-generation process of its incubatees. The Director of Innovation, whom we met, was convinced of this approach's effectiveness:[On the change of state of dynamics] Yes definitively! The combination of visibility on the project, constraints (fewer resources, frugality), the need for a more resourceful mind ... all of these generate more innovations.

\section{ii. Knowledge articulation}

In IPC A, we have identified two methods for articulating the entrepreneurial knowledge developed within the incubator. One is that incubatees often had to explain what they were doing when they were soliciting IPC's employees to help them with different tasks. The second is that at the end of their incubation experience, incubatees were to have a feedback session with the person in charge of the incubation program.

With regard to the collaboration between IPC B's employees and incubatees, the latter encountered various obstacles in obtaining the necessary resources for their projects, i.e., to contact clients or build prototypes. They had to explain what they were doing and demonstrate the added value. During the incubation period, they were confronted with misconceptions on the part of some employees, but this nevertheless, contributed, in our opinion, to highlight the advantage of using an incubation program to inject entrepreneurial momentum into an IPC's innovation processes.

Incubatees' feedback about their incubation experience had not yet been collected by IPC $\mathrm{C}$ at the time of our interviews. The incubatees were focused on their projects rather than on the incubation model itself, but a discussion session on the experiment was planned between at least one of the incubatees that we met and the incubator manager. In IPC D, we have no examples of knowledge articulation.

\section{iii. Knowledge codification}

Interviews conducted with the incubatees of IPC A indicate that they did not spend much time codifying their experience in the incubator. Although they were motivated to do so, priority was given to the rapid development of the project on which they were working:

I was hired because I am an entrepreneur and I come from the world of startups. For us, we follow this process intuitively. When you are a start-up, you have a problem, a solution, you validate it. Let's start with engineering to see how much it will cost, then let's see a couple of customers to test it. In short, we do it intuitively.

The above quote shows a certain incompatibility between the process of knowledge codification, which requires higher levels of cognitive effort, and entrepreneurial mindset, which is decision- and risk-oriented. However, as was the case in IPC C, the innovation manager was involved in knowledge codification as evidenced by the evolution of the incubation program in response to the first cohort feedback. With regard to 
IPC D, we do not have enough data to be able to document the knowledge codification in their case.

c. Impact on innovation capability

\section{i. Resources}

Tangible results of innovation were observed in both IPC A and IPC D. In the former, one project was being reintegrated into a business unit while a second project was entering the test phase with a client/partner. In the latter, the innovation director noted a significant acceleration in vaccine development timelines through incubation. The impact on resources, however, seems to have been much greater in IPC A. Incubation would have enabled IPC A to learn how to capitalize on its wealth of assets in a different way. By looking for new ways to exploit the company's resources, with more than 8000 employees and important communications infrastructures around the world, incubatees have succeeded in creating original combinations that may meet their employer's challenges. The impact of incubation on IPC D's resources seems to enhance the entrepreneurial dynamic not by creating a new mix of resources, but by the frugality it puts forward: "The way you work in the incubator, first and foremost, we work frugally. Frugal in time and resources."

\section{ii. Process}

As mentioned, incubation does have an impact on the IPC A process, as it acts as a pilot project to test new product development methods, which are based on the principles of Lean Start-up (Ries, 2011) and the Business Model Canvas (Osterwalder \& Pigneur, 2010). Their underlying principles are to ensure a single-minded focus on the customer's unsolved problem and take a hypothesis-driven and iterative approach to find scalable solutions.

These entrepreneurial practices may seem very different from the IPC's core activities. Their most significant impact would be to completely reverse the IPC A's innovation philosophy by shifting it from an approach of imposing highly efficient technologies on the market (market push) to an approach based on identifying needs and providing solutions by means of accumulated knowledge (market pull). Therefore, we expect a direct impact of the entrepreneurial mindset fostered in the incubator on the IPC A's innovation processes.

Within IPC D, we note a more limited impact, particularly because of the nature of the industry in which this company operates. As mentioned earlier, this is a highly regulated industry where risk management is given very careful consideration because products are designed to prevent disease.

iii. Values

Christensen $(1997,2013)$ argues that values, as a dimension of a dynamic capability such as innovation, are the criteria by which a company's employees prioritize markets 
or business opportunities. At IPC A, entry into adjacent markets is only considered if the company can capitalize on its assets and capabilities, and there is a substantial growth opportunity for this $\$ 2.3$ billion company. The selection criteria for an idea to be incubated require it to potentially generate quick revenues of over $\$ 200$ million a year. Projects that fail to reach this target are either reintegrated into the parent company, which is nevertheless a tangible result or simply abandoned. Thus, in terms of the size of the markets worthy of interest for the IPC A, we did not note any evolution of values.

Furthermore, as we discussed, through internal incubation, this company seeks to open up to new segments of clientele and offer a value proposition that moves away from what the company traditionally does offers. For example, one incubation project that, at the time of our interviews, was entering the test phase involved a form of mobile banking service for disadvantaged or marginalized people whose business model was based on IPC A's current customer base and communications infrastructure:

What I want to test is to increase our ability to sell a product that we are not familiar with at all. So, in the end, there is a process of internal maturation, there's also a process of discovery, so that's where I'm at. In this case, it is not the technology that is innovative. We are talking about mobile platforms; we are talking about API. In this case, what is innovative is the set of technologies/business models and partnerships at stake. That's what we sell.

In IPC D, we have no evidence that the target markets or the size of the opportunities pursued differed from the traditional focus of the company. For the IPC D's director of innovation, the incubator was set up to "turn creativity into a potential innovation for our society."

\section{Retention within IPC B}

The final step in the evolution model of deliberate learning (Zollo \& Winter, 2002) is the retention phase, where codified knowledge is embedded and institutionalized. Repetition leads to the automatic execution of tasks and thus to the reduction of individual awareness of the link between the task and its raison d'être (Zollo \& Winter, 2002).

\section{a. Level of influence observed}

While the objective of the IPC B in launching an internal incubator was primarily to develop new markets and less to transform its organizational culture, the incubation experience has enabled the retention of entrepreneurial mindset. According to the testimonies we have received, IPC B has effectively moved from a passive business strategy focused on executing mandates for its current clients to an active corporate strategy ${ }^{2}$ focused on seizing opportunities and conquering new markets. By using an effectual approach (Sarasvathy, 2001) for its incubation initiative, IPC B strengthened its ability to penetrate adjacent markets, such as aviation, and then began to be much more aggressive in seeking emerging opportunities in terms of market diversification. We present how this transformation took place. 


\section{b. Learning mechanisms}

i. Knowledge accumulation

As we have seen, incubation has proved to be, unanimously in our sample, a source of accumulated experience for both incubatees and the innovation managers in charge of the corporate incubators. Unsurprisingly, we see the same phenomenon in IPC B. The entrepreneurial methods learned and put into practice appeared counter-intuitive for the incubatees we interviewed, but effective in identifying new markets and understanding the needs of consumers targeted by the proposed project idea:

We were told: 'You have an electric airplane project, we're going to put it aside and instead look at what market you're talking about, what market you're going to go to, and you're going to meet them directly'. And so we were on day three to go to the aerodromes in Belgium to ask our questions and understand what are the problems they encounter. Before coaching, we would have tended to go for a solution that we thought was appropriate. Now, what we've been taught is that no matter what we want to do, what we need to do is to have a market and people who are interested in this idea.

In fact, the accumulated experience was so transformative, and the idea pursued so compelling that the team decided that with or without the support of their IPC, they would carry out their plan to commercialize a small aircraft:Since we were a pilot

project, there were no rules. And so when it became more and more concrete, we thought this is it, we believe in it and will launch with or without them [IPC B].

It must, therefore, be admitted that by responding to external environmental stimuli with new methods, the incubatees' exploration efforts enabled them to master new product development routines that proved successful in their particular context.

\section{ii. Knowledge articulation}

Despite the success of the first project incubated by IPC B, we determine that the articulation of knowledge was rather average. Incubatees were fully absorbed in their projects and did not have time to share their experience with their colleagues in the IPC B. Some more formal channels did exist, and they tried to exchange perspectives on an ad hoc basis, but in a limited way:

What we didn't get a chance to do because we got into our thing. We did it with a few people who asked us questions, but we don't have time to do it all the time.

That said, we retain two elements that have certainly contributed to the articulation of knowledge developed through the first incubation experiment set up by the IPC B. First, one of the incubatees involved in the project we mentioned chose to withdraw before the spin-off. Unlike his partners, the incubatee had the opportunity to transmit to the IPC the methods acquired during the incubation. Second, a transversal 
evaluation committee was set up by IPC B to ensure optimal communication and prioritization of the incubation initiative throughout the organization.

\section{iii. Knowledge codification}

IPC B is the company we rank as having the highest level of knowledge codification, not only because incubatees have documented their incubation experience but also due to the assistance of a university professor specializing in innovation. In addition, we notice a definite codification of learning through the modifications made to the incubation model. Ultimately, the combination of knowledge accumulation, articulation, and codification has enabled the IPC B to infuse its innovation capability with an entrepreneurial mindset.

c. Impact on innovation capability

\section{i. Resources}

The impact of internal incubation on the resources pertaining to IPC B's innovation capability manifested itself in three ways. First, IPC B adopted a partnership approach with other companies to access competencies it did not possess in order to carry out innovation projects. Second, and this time it is a negative impact, the IPC B lost the human resources it has developed through incubation by spinning-off the project. While the former incubatees are still linked to the IPC B, which owns over $50 \%$ of the subsidiary they have created, they do not participate in the dissemination of incubation knowledge within the IPC. Third, by setting up the subsidiary, IPC B has acquired new capabilities linked to the commercialization of small aircrafts, a sector in which it has historically not ventured.

\section{ii. Process}

The incubation had a clear impact on how IPC B was conducting its innovation processes. The willingness to make changes was first expressed by the organization's senior management, but it was really through action that the processes were able to evolve:

The main message of the meeting was: IPC B wants to diversify through innovation and you, the company's executives, will have the opportunity to lead different projects. We don't do by the textbook. We learn day by day. We are rather pragmatic, and here we are. We do notice shortcomings, but I find that it is a method that also defends itself because we learn quickly, and we are immediately operational.

Christensen (1997) argues that processes are not flexible being used to effectively perform a task, no matter who performs it. However, we find that, through incubation, IPC B has evolved from a company focused on gradually improving processes in component machining to a company focused on growth through diversification. 


\section{iii. Values}

The internal incubation program has had a clear influence on IPC B's organizational values. By validating its potential to leverage some of its capabilities to enter sectors of activity adjacent to its traditional activities, IPC B has demonstrated that it can replicate this practice successfully.

\section{Discussion}

\section{Theoretical implications}

According to our conceptual framework inspired by Zollo and Winter's (2002) deliberate learning model, the investments in the three learning mechanisms, i.e., knowledge accumulation, articulation, and codification, should enable the entrepreneurial mindset fostered by incubators to drive the evolution of IPC's innovation capability. This evolution was to take place in four consecutive steps: (1) generative variation, (2) internal selection, (3) replication, and (4) retention. The retention level was achieved only by IPC $\mathrm{B}$, which is also the company that has best assimilated the entrepreneurial mindset fostered by its corporate incubator.

While all the incubation initiatives in the cases studied proved to be very successful in terms of knowledge accumulation, IPC B distinguished itself from the other IPCs by the extra effort put into the articulation and codification of the knowledge resulting from the incubation experience. By creating a cross-functional committee to ensure incubator's development and management and then by calling on an external observer, IPC B reinforced the legitimacy perception of its incubation initiative in the eyes of the various corporate executives. These factors undoubtedly contributed not only to facilitate the internal selection stage but also to identify the practices to be adapted to replicate entrepreneurial mindset and methods in the different dimensions of the IPC's innovation capability.

The difficulties that the other IPCs we studied encountered in implementing these learning mechanisms demonstrates that they were not prepared to absorb the learning resulting from incubation. Rather, they focused on creating precedents that demonstrate that incubation is indeed effective in developing new products/services and business models. However, if knowledge articulation is achieved only through feedback, projects will take precedence over learning, as observed in cases A, C, and D, and knowledge will then be less likely to be transferred to the IPC.

It is important to note, however, that achieving the retention stage is not the only level that can have an impact on all three dimensions of the innovation capability. IPC $\mathrm{B}$ and D's cases demonstrate that at the replication stage, the entrepreneurial mindset, and methods fostered in the incubator have already influenced the innovation capability of their IPC. In some contexts, the entrepreneurial mindset is simply not compatible with the functioning of an organization because of the complexity of its operations or the effect of different regulations on its activities. In this context, certain values, in terms of target markets or prioritizing certain operations to the detriment of others, need to be preserved. However, this does not prevent the entrepreneurial mindset from influencing the resources available in the organization or its processes.

Thus, the deliberate learning cycle of variation, internal selection, replication, and retention expresses how an IPC can detect and capture the entrepreneurial mindset present in its incubator in order to infuse it into the resources, processes, and values 
that underpin its capabilities. Not all the IPCs studied reached each of the above steps, but we believe they were all motivated to do so since, at the time of the interviews, they were all working on changes to their incubation model. The willingness to change the incubation model pushes us to recognize one missing element in our theoretical framework that may be fundamental to the successful diffusion of entrepreneurial mindset through incubation. This is the method of recruiting incubatees, which was one of the key factors in the success or failure of incubation initiatives. Indeed, in three of the cases studied, the changes made in the incubation model following the first cohort experience were linked to the identification of people (employees) most likely to carry out an entrepreneurial project. In the other case, the IPC specifically designed the recruitment model to identify people with strong entrepreneurial potential.

We have shown that each incubatee accumulated new knowledge through incubation. Moreover, we provided examples demonstrating that not all individuals suffused with this knowledge were able to act entrepreneurially, which proves the relevance of an incubation model based on entrepreneurial mindset. This does not imply that entrepreneurial mindset and methods cannot be institutionalized over time, but to have a timely impact and thus demonstrate its value, entrepreneurial mindset must already be present in the recruited incubates. This mindset encourages "product championing" and "strategic forcing" behaviors inherent in the incubation process and essential to the success of projects (Burgelman, 1983).

\section{Implications for research}

We focused our research on the incubation of employees' projects. It would also be worthy of further study to analyze the impact of hosting start-ups or outside entrepreneurs in a corporate incubator. Given that the recruitment of incubates has become a key factor in the performance of the incubation program, we question the potential legitimacy of such a practice in the eyes of a company's employees. This questioning is relevant because, in our opinion, it brings us closer to the currently dominant approaches in innovation management, namely open innovation (Chesbrough, 2006) and co-creation (Ramaswamy \& Gouillart, 2010). While the latter relies on the permeability of companies' boundaries to their environment and the establishment of engagement mechanisms to foster the active participation of their stakeholders in the innovation process, it would be interesting to study the applicability of these concepts to established business incubation practices.

Finally, it would be imperative to establish whether incubators can enable companies to overcome the innovator's dilemma as expressed by Christensen (1997). Is the efficient operation of an internal incubator sufficient for a company to better prepare itself to face the disruption of its industry by new technologies or new business models, or to adapt quickly enough to ensure its survival?

Until researchers can provide answers to these questions, we can only discuss some implications of our own research for practitioners.

\section{Implications for practice}

Based on our findings, we have five suggestions for practitioners involved in setting up and managing corporate incubators. First, with respect to recruitment, we believe it is 
essential to identify and recruit motivated individuals to build a project and take advantage of the autonomy they are granted to accelerate the pace of product/service/business model development for their parent organization. Entrepreneurial individuals contribute to the achievement of tangible results and thus to the legitimacy of the incubator within the company.

Second, incubator managers must facilitate a significant accumulation of experience for incubatees. Beyond the autonomy granted in time and budget management, it is also necessary to maintain a climate of frugality and precariousness in order to encourage creativity among incubatees. We also recommend both incubator managers and incubatees document their experience in order to highlight what they regard as their most significant acquired knowledge and the means they deem most appropriate to benefit from them.

Third, the organization setting up an incubator must encourage collaboration between its incubatees and its other employees. The advantage of fostering collaboration is the improved articulation of knowledge between incubatees and the employees of the parent organization. By working together on a project, incubatees can share their entrepreneurial know-how, while IPC employees can assess the advantages or disadvantages of these new practices. The legitimacy of the know-how developed in the incubator is thus strengthened.

Finally, the incubation initiative should be led by the company's head. It was clear from our study that a lack of legitimacy can be a major impediment to achieving tangible results through incubation. If an IPC's employees are not encouraged to prioritize incubatees' requests, nor to help them, the opportunities for knowledge transfer and sharing between them are substantially limited.

\section{Conclusion}

Summing up, our study shows that corporate incubation is not only a viable way for established companies to explore new ideas for their business innovation efforts but also a valuable tool with the potential to instill entrepreneurial mindset in a company's employees. The entrepreneurial spirit transmitted to employees will ultimately lead to the evolution of the company's innovation capability. We have demonstrated by drawing on Zollo and Winter's (2002) deliberate learning model that the knowledge that is achieved in a corporate incubator can effectively be seized and influence the IPC's innovation capability, provided that the necessary mechanisms for its absorption are in place.

One aspect that emerged from each of the cases studied is missing from Zollo and Winter's (2002) deliberate learning model. This is the recruitment method of incubates, because beyond the learning mechanisms associated with implementing new approaches, recruitment has been one of the key factors in the success or failure of incubation initiatives.

We have shown that each of the incubates has accumulated new knowledge through corporate incubation. In addition, we proposed examples showing that not everyone infused with this knowledge could necessarily act entrepreneurially and thus show the value of a model based on entrepreneurial mindset. This does not imply that entrepreneurial mindset cannot be institutionalized over time, but in order to have a rapid 
impact and thus show its value, an entrepreneurial mindset should already be present among the participants recruited for corporate incubation.

More importantly, our study opens up new avenues of research that encourage the bridging of fields of study in innovation management and organizational entrepreneurship. We suggested a number of questions be considered by researchers interested in these topics, which we believe are relevant at a time when accelerating technological change is forcing companies to transform more intensely and more rapidly than ever before.

\section{Endnotes}

${ }^{1}$ We have chosen a broad definition of organizational culture, as proposed by the Board of Canada, i.e. the systems, processes, technologies, and measures that are the fabric of how an organization works in addition to the shared values, beliefs, assumptions, and artifacts of an organization (Assad, Brooke Dobni, Colby, \& Ozyildirim, 2017).

${ }^{2}$ Business strategy focuses on how to reach and satisfy customers, deliver goods and services that meet their needs and increase turnover. Corporate strategy seeks to achieve a combination of business units that will enable the company to succeed as a whole.

\section{Abbreviations}

IPC: Incubator's parent company; RPV: Resource-processes-values

\section{Acknowledgements}

We are grateful to Professor Laurent Simon (HEC Montréal) who helped us to participate in The Mosaic MontrealBarcelona Creativity Summer School where we were able to identify three cases that are part of this research and who accompanied us throughout this experience.

\section{Funding}

This research received no specific grant from any funding agency in the public, commercial, or not-for-profit sectors.

\section{Availability of data and materials}

The raw/processed data (interviews records and transcripts) cannot be shared at this time due to confidentiality reasons (the four companies that formed our sample would be easily identifiable).

\section{Authors' contributions}

JG collected the data and conducted a literature review. GMC wrote the paper. JG (70\%) and GMC (30\%) worked on the theoretical framework and data interpretation. Both authors read and approved the final manuscript.

\section{Competing interests}

On behalf of all authors, the corresponding author states that the authors have no significant competing financial, professional, or personal interests that might have influenced the performance or presentation of the work described in this manuscript.

\section{Publisher's Note}

Springer Nature remains neutral with regard to jurisdictional claims in published maps and institutional affiliations.

\section{Author details}

${ }^{1}$ HEC Montréal, 3000, chemin de la Côte-Sainte-Catherine, Montreal, QC H3T 2A7, Canada. ${ }^{2}$ Université du Québec à Rimouski (UQAR), 300, allée des Ursulines, Rimouski, QC G5L 3A1, Canada.

Received: 1 November 2018 Accepted: 28 February 2019

Published online: 15 March 2019

\section{References}

Assad, V., Brooke Dobni, C., Colby, E. \& Ozyildirim, A. (2017) Insights from highly innovative companies, global state of innovation survey 2017, Research Report, InnovationOne, available at: https://www.conferenceboard.ca

Becker, B., \& Gassmann, O. (2006). Gaining leverage effects from knowledge modes within corporate incubators. R\&D Management, 36(1), 1-16.

Bird, B. J. (1989). Entrepreneurial Behavior. London: Scott, Foresman. 
Block, Z., \& Stumpf, S. A. (1990). Entrepreneurship education research: Experience and challenge. New York: Center for Entrepreneurial Studies, New York University, Leonard N. Stern School of Business.

Burgelman, R. A. (1983). A process model of corporate venturing in the diversified major firm. Administrative Science Quarterly, 28(2), 223-244.

Chesbrough, H. W. (2006). Open innovation: the new imperative for creating and profiting from technology. Boston Massachusetts: Harvard Business Press.

Christensen, C. (2013). The Innovator's dilemma: when new technologies cause great firms to fail. Boston Massachusetts: Harvard Business Review Press.

Christensen, C. M. (1997). The Innovator's dilemma. Boston: Harvard Business School Press.

Christensen, C. M., Anthony, S. D., \& Roth, E. A. (2004). Seeing What's next? Using the theories of innovation to predict industry change. Boston: Harvard Business School Press.

Criscuolo, P., Nicolaou, N., \& Salter, A. (2012). The elixir (or burden) of youth? Exploring differences in innovation between start-ups and established firms. Research Policy, 41(2), 319-333.

Dobbs, R., Manyika, J., \& Woetzel, J. (2016). No ordinary disruption: the four global forces breaking all the trends. New York: Public Affairs.

Eisenhardt, K. M. (1989). Building theories from case study research. Academy of Management Review, 14(4), 532-550.

Ford, S., Garnsey, E., \& Probert, D. (2010). Evolving corporate entrepreneurship strategy: technology incubation at Philips. R\&D Management, 40(1), 81-90.

Haynie, J. M., Shepherd, D., Mosakowski, E., \& Earley, P. C. (2010). A situated metacognitive model of the entrepreneurial mindset. Journal of Business Venturing, 25(2), 217-229.

Keil, T., McGrath, R. G., \& Tukiainen, T. (2009). Gems from the ashes: capability creation and transformation in internal corporate venturing. Organization Science, 20(3), 601-620.

Klapper, R., \& Leger-Jarniou, C. (2006). Entrepreneurship intention among French Grande École and university students: an application of Shapero's model. Industry and Higher Education, 20(2), 97-110.

Klinger, B., \& Schundeln, M. (2011). Can entrepreneurial activity be taught? Quasi-experimental evidence from Central America. World Development, 39(9), 1592-1610.

Kohler, T. (2016). Corporate accelerators: building bridges between corporations and start-ups. Business Horizons, 59(3), 347357.

Miles, M. B., \& Huberman, A. M. (1994). Qualitative data analysis: an expanded sourcebook. Thousand Oaks: Sage Publications.

Osterwalder, A., \& Pigneur, Y. (2010). Business model generation: a handbook for visionaries, game changers, and challengers. Hoboken: Wiley.

Ramaswamy, V., \& Gouillart, F. J. (2010). The power of co-creation: build it with them to boost growth, productivity, and profits. New York: Free Press, a division of Simon and Schuster.

Ries, E. (2011). The lean start-up: how today's entrepreneurs use continuous innovation to create radically successful businesses. New York: Crown Books.

Roessler, M., \& Velamuri, S. R. (2015). Corporate Incubation as a Tool to Foster Business Model Innovation. ISPIM Conference Proceedings. The International Society for Professional Innovation Management (ISPIM).

Sarasvathy, S. D. (2001). Causation and effectuation: toward a theoretical shift from economic inevitability to entrepreneurial contingency. Academy of Management Review, 26(2), 243-263.

Teece, D. J. (2007). Explicating dynamic capabilities: the nature and microfoundations of (sustainable) Enterprise performance. Strategic Management Journal, 28(13), 1319-1350.

Teece, D. J., Pisano, G., \& Shuen, A. (1997). Dynamic capabilities and strategic management. Strategic Management Journal, 18(7), 509-533.

Tushman, M. L., \& O'Reilly III, C. A. (1996). Ambidextrous organizations: managing evolutionary and revolutionary change. California Management Review, 38(4), 8-29.

Tushman, M. L., \& O'Reilly III, C. A. (2004). The ambidextrous organization. Boston: Harvard Business Review.

Vanhaverbeke, W., \& Peeters, N. (2005). Embracing innovation as strategy: corporate venturing, competence building, and corporate strategy making. Creativity and Innovation Management, 14(3), 246-257.

Velamuri, S. R. (2002). Entrepreneurship, altruism, and the good society. The Ruffin Series of the Society for Business Ethics, 3, $125-142$.

Verstraete, T., \& Fayolle, A. (2005). Paradigmes et entrepreneuriat. Revue de l'Entrepreneuriat, 4(1), 33-52.

Von Hippel, E. (1977). Successful and failing internal corporate ventures: an empirical analysis. Industrial Marketing Management, 6(3), 163-174.

Von Zedtwitz, M. (2003). Classification and management of incubators: aligning strategic objectives and competitive scope for new business facilitation. International Journal of Entrepreneurship and Innovation Management, 3(1), 176-196.

Wang, C. L., \& Ahmed, P. K. (2007). Dynamic capabilities: a review and research agenda. International Journal of Management Reviews, 9(1), 31-51.

Weiblen, T., \& Chesbrough, H. W. (2015). Engaging with start-ups to enhance corporate innovation. California Management Review, 57(2), 66-90

Yin, R. (2009). Case study research: design and methods. 4th Edition. Thousand Oaks: Sage.en.

Zahra, S. A., Nielsen, A. P., \& Bogner, W. C. (1999). Corporate entrepreneurship, knowledge, and competence development. Entrepreneurship Theory and Practice, 23(3), 169-189.

Zollo, M., \& Winter, S. G. (2002). Deliberate learning and the evolution of dynamic capabilities. Organization Science, 13(3), $339-351$. 